\title{
Chúng ta cần biện pháp nhanh, mạnh để có thể ổn định khí hậu toàn cầu
}

- sciencevietnam $\quad F$ Cuộc sống (1) August 11,2021

ENHANCED BY Google

SSHPA (11-08-2021) — Báo cáo Sixth Assessment Report (AR6) mới nhất của Ban liên chính phủ về biến đổi khí hậu (Intergovernmental Panel on Climate Change, hay IPCC) đánh giá sự thay đổi khí hậu và môi trường trên thế giới hiện nay là chưa từng có tiền lệ trong hàng ngàn, thậm trí trăm ngàn năm $[1,2]$.

Về sự kiện này, báo Tuổi trẻ cho biết [3]:

"Những trận bão nhiệt đới trở nên mạnh hơn, trong khi băng ở Bắc cực đang giảm dần vào mùa hè và lớp băng vĩnh cửu cũng tan ra. Tất cả những xu hướng này sẽ ngày càng tồi tệ.

Một ví dụ là loại sóng nhiệt chỉ xảy ra với tần suất 50 năm một lần giờ xuất hiện mỗi thập kỷ. Và nếu thế giới ấm thêm 1 độ $C$ nữa, sóng nhiệt sẽ xảy ra với tần suất 7 năm."

Theo nhà nghiên cứu Panmao Zhai, đồng chủ trì IPCC Working Group I, thì chúng ta cần biện pháp giảm thiểu khí thải mạnh, nhanh chóng và bền vững để có thể ổn định khí hậu toàn cầu [2]. Trong đó, tận dụng khả năng của giới doanh nghiệp và thay đổi văn hóa là những giải pháp tiềm năng $[4,5]$. 


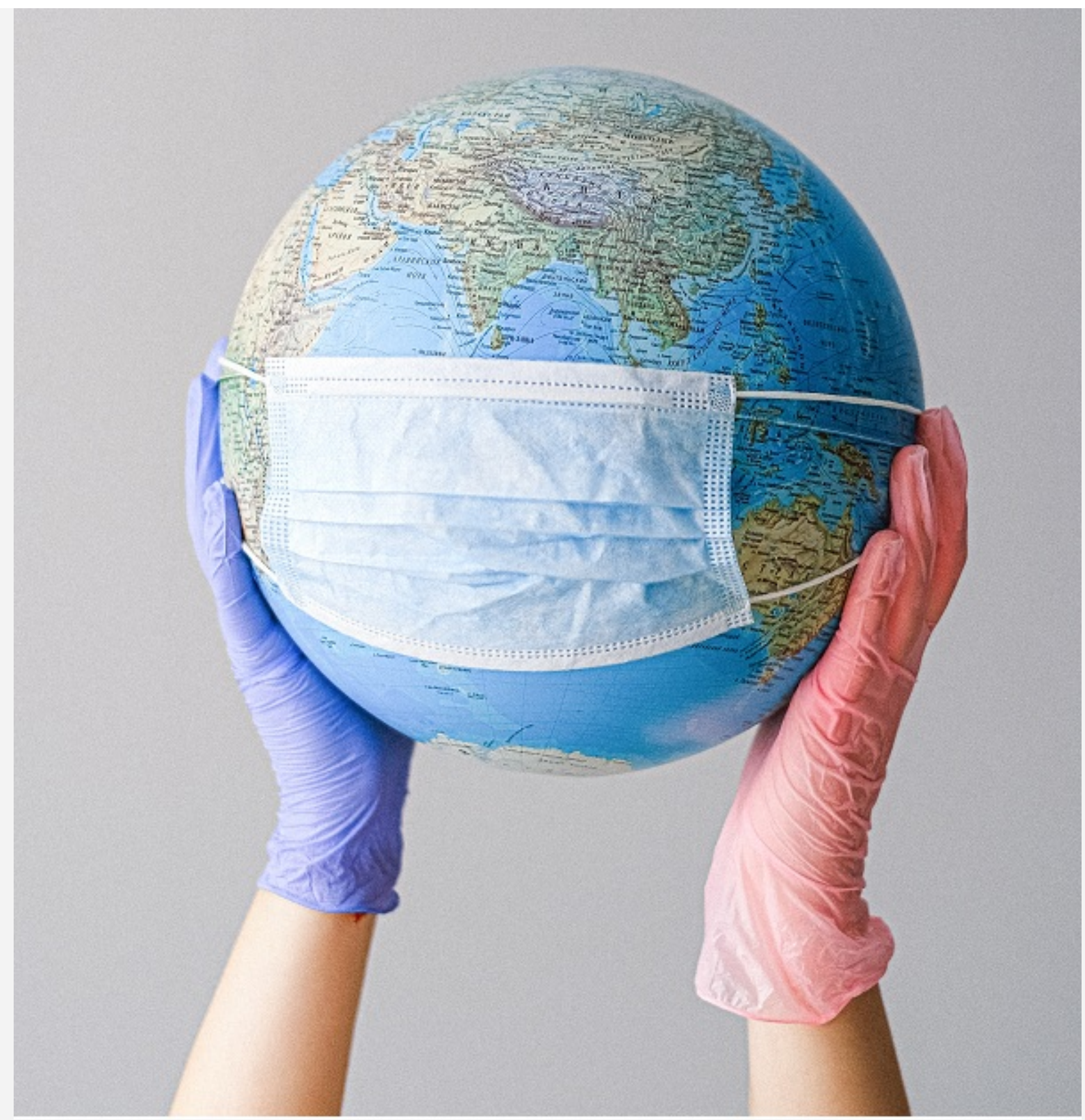

Ảnh của Anna Shvets từ Pexels

Báo cáo Sixth Assessment Report (AR6) của IPCC do một hội đồng gồm 234 tác giả tới từ 66 quốc gia: 31 tác giả điều phối, 167 tác giả dẫn dắt, và 36 biên tập viên phản biện [2,3]. Đồng thời, 517 nhà khoa học khác cũng tham gia đóng góp. Báo cáo AR6 tham khảo hơn 14000 tài liệu, và ý kiến từ 78007 chuyên gia.

\section{Tài liệu tham khảo:}

[1] Working Group I. (2021). Sixth Assessment Report, Climate Change 2021: The Physical Science Basis. IPCC. URL: https://www.ipcc.ch/assessment-report/ar6/

[2] IPPC. (2021). Climate change widespread, rapid, and intensifying - IPCC. IPCC. URL: https://www.ipcc.ch/2021/08/09/ar6-wg1-20210809-pr/

[3] Bình Giang. (2021). 234 nhà khoa học cảnh báo thảm hoạ của thế giới. Tuổi trẻ. URL: https://tienphong.vn/234-nha-khoa-hoc-canh-bao-tham-hoa-cua-the-gioipost1364350.tpo

[4] Vuong QH. (2021). The semiconducting principle of monetary and environmental values exchange. Economics and Business Letters, 9(3), 284-290. 
[5] Vuong QH, et al. (2021). Identifying the moral-practical gaps in corporate social responsibility missions of Vietnamese firms: an event-based analysis of sustainability feasibility. Corporate Social Responsibility and Environmental Management, 28(1), 30-41.

(1) Last modified: 8/11/20216:27 PM O Views: 0 ff 0 y 0

\section{Bài liên quan:}

- Trong Rừng Dẻ Gai, nhà văn Nguyễn Thị Ngọc Tú và bài báo quốc tế

- Từ quá khứ tới thực tại, từ tư tưởng tới hành động phát triển kinh tế xanh

- Bảo vệ môi trường: Không có cơ chế để "đổi chác các bù"

- Tam đề nan giải phát triển công nghiệp bền vững

- Nhóm tác giả Việt nghiên cứu mô hình SDGs Kitakyushu

\section{Ý kiến bạn đọc (0):}

Comment

Gửi bình luận

(c) 2018 - 2021 EASE Vietnam SciComm System. All rights reserved. Powered by Vuong \& Associates. Built to serve the social sciences and humanities. 